\title{
A rapid heating and high magnetic field thermal analysis technique
}

\author{
Michael S. Kesler ${ }^{1} \mathbb{D} \cdot$ Michael A. McGuire $^{1} \cdot$ Ben Conner $^{1} \cdot$ Orlando Rios $^{1,2} \cdot$ Bart Murphy $^{1} \cdot$ William Carter $^{1}$. \\ Hunter B. Henderson ${ }^{3}$. Gerard M. Ludtka ${ }^{1} \cdot$ Roger A. Kisner ${ }^{4}$
}

Received: 28 May 2020 / Accepted: 11 July 2021 / Published online: 5 September 2021

(c) The Author(s) 2021

\begin{abstract}
A new thermal analysis technique is described that allows measurements to be performed on bulk samples at extreme heating and cooling rates and in high magnetic fields. High heating rates, up to $1000{ }^{\circ} \mathrm{C} \mathrm{min}^{-1}$, are achieved through electromagnetic induction heating of a custom-built apparatus fitted with commercial thermal analysis heads and sensor. Rapid cooling rates, up to $100{ }^{\circ} \mathrm{C} \mathrm{min}^{-1}$, are enabled by gas quenching and the small thermal mass of the induction furnace. The custom apparatus is designed to fit inside a superconducting magnet capable of fields up to 9 Tesla. This study demonstrates that the instrument is capable of collecting accurate thermal analysis data in high magnetic fields and rapidly acquiring data for dynamic processes. While the full potential of the technique is still unrealized, currently, it can provide insight into phenomena at time scales relevant to heat treatment in many industrial processes and into little understood effects of high magnetic field processing.
\end{abstract}

Keywords Static magnetic field · Thermal analysis $\cdot$ Thermomagnetic processing $\cdot$ Transformation kinetics

\section{Introduction}

Differential scanning calorimetry (DSC) is an important characterization technique for identifying phase transformation temperatures and quantifying heat capacity and transformation enthalpy. Since its development in the 1960's [1, 2], advancements in this technique include signal amplification, rapid heating rates, various data analysis methods, and environment versatility. Currently, rapid heating and cooling rate thermal analysis techniques are of scientific interest and high industrial relevance particularly to the medical and pharmacological fields $[3,4]$. Thermal analysis at extreme heating rates (in some cases exceeding $10^{4}{ }^{\circ} \mathrm{C} \mathrm{min}^{-1}$ ) has been developed in recent decades and is a common technique to

Michael S. Kesler

keslerms@ornl.gov

1 Oak Ridge National Laboratory, 1 Bethel Valley Rd, Oak Ridge, TN 37830, USA

2 Department of Materials Science and Engineering, University of Tennessee, Knoxville, TN 37996, USA

3 Lawrence Livermore National Laboratory, Livermore, CA 94550, USA

4 Aether Spectrum LLC, 3223 Meadowrun Lane, Knoxville, TN 37931, USA investigate kinetic effects in polymers and some low melting temperature metallic materials [5-10]. These rates are achievable due to the direct application of current to a thin film for testing samples (thin films and droplets) up to several tens of nanometers. With other recent DSC instrumentation, samples sizes on the order of $1 \mathrm{mg}$ can be measured at several hundred ${ }^{\circ} \mathrm{C} \min ^{-1}$ heating rates $[3,8,11-13]$, but larger samples in conventional DSCs tend to experience significant thermal lag at heating rates $>100{ }^{\circ} \mathrm{C} \mathrm{min}^{-1}$ due to high thermal mass of both sample and furnace. While the aforementioned techniques can provide scientific insight into many material systems, the ability to evaluate bulk scale specimens at rapid rates would expand the relevance to a broader range of applications.

Calorimetric measurements are commonly used to examine the effect of external fields on phase transformations. In particular, magnetic fields can have a strong effect on the microstructural evolution of materials during thermal processing. Calorimetric measurements in high magnetic fields are routinely used in condensed matter physics, particularly with small samples at cryogenic temperatures. Larger scale, low melting point metallic specimens have been analyzed at high non-static fields using differential thermal analysis (DTA) $[14,15]$, though scanning rates and temperatures directly relevant to many engineering applications and 
industrial processes have yet to be explored because of the numerous technical challenges. Further motivating experiments in high static field thermal analysis are the observations of significant rate and magnetic field-dependent changes in microstructural morphology and phase equilibria that have been observed from microstructural analysis and dilatometry. These observations have been described theoretically through evaluation of the magnetic component in Gibbs free energy [16-26].

To extend conventional thermal analysis measurements to higher rates, the furnace must be robust enough to provide rapid heating, uniform hot zone, and high maximum temperature. For larger sample sizes $(25-500 \mathrm{mg})$, this results in relatively high total thermal mass. The temperature response of calorimeters can be enhanced by limiting the system's thermal mass and, thus, the application of induction heating in place of resistive heating can provide a compact heating element with high energy density capable of heating rates exceeding $1000{ }^{\circ} \mathrm{C} \mathrm{min}^{-1}$.

In addition to limiting thermal mass, the compact format of an induction furnace is compatible with high field thermomagnetic processing where space is limited in the cylindrical bore of superconducting magnets (commonly less than $15 \mathrm{~cm}$ in diameter for magnets capable of $>7 \mathrm{~T}$ ). Induction coupled thermomagnetic processing $[27,28]$ is a versatile approach for investigating the effects of applied magnetic fields during heat treatments.

Here, we combine the benefits of induction heating with commercial thermal analysis hardware to achieve accurate measurements at extreme heating rates in an instrument that is compatible with high magnetic fields. This enables the study of kinetic effects at time scales comparable with industrial processing protocols and increased insight into the effects of high magnetic fields on phase transformations during thermomagnetic processing.

\section{Magnetic field/high rate thermal analyzer}

\section{Instrument design}

The novel aspects of this technique, operation in high magnetic fields and at high heating and cooling rates, require the development of a non-magnetic apparatus that is compatible with a commercial warm bore superconducting magnet and has a small thermal mass and high heating efficiency [29]. As noted above, the latter requirement is satisfied by employing induction heating. The thermal analyzer is placed inside a vertically aligned American Magnetics, Inc. superconducting magnet with a $127 \mathrm{~mm}$ bore fitted with an induction coil. The Magnetic Field/ High Rate Thermal Analyzer (MFHR-TA) system was designed around a commercial SETARAM head that fits SETSYS Evolution compatible S-type DSC and DTA sensors with standard crucibles. The head, with an electrical feedthrough and a gas inlet, seals to the top of a $60 \mathrm{~mm}$ diameter quartz tube with a gas outlet on the bottom.

Figure 1a shows a schematic cutaway and cross section of the MFHR-TA apparatus. The outermost layer is the quartz tube which provides the sealed environment. Moving radially inward, there lies a layer of insulating refractory fabric to protect the induction coil from the direct radiative heating and provide thermal insulation for the exterior silica tube. This insulating fabric experiences high temperatures and should be silica-free, since volatile Si-containing species will react with Pt-based wires and
Fig. 1 Schematic of the a thermal analyzer assembly, and b induction coil insert and large bore superconducting magnet. The thermal analyzer assembly is placed inside the induction coil insert (a)

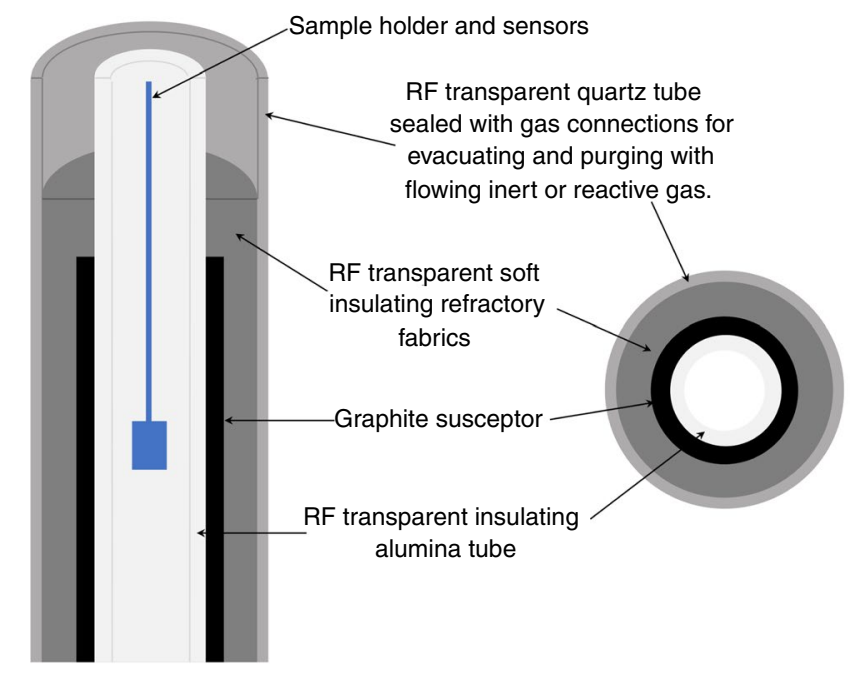

(b)

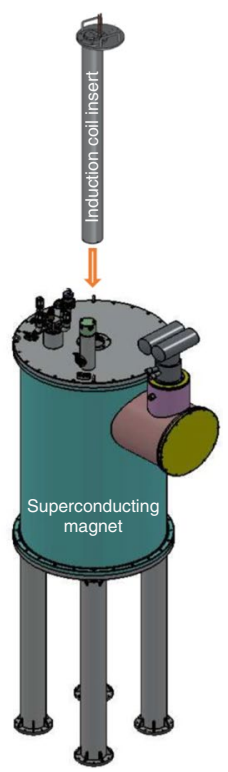


drastically shorten the life of the sensors. Zirconia-based insulation is used for this purpose. The black layer represents the graphite susceptor (3.2 mm wall thickness) which absorbs the electromagnetic energy from the induction coil and acts as the heat source. The susceptor also acts as an RF shield, protecting the sensor and samples from significantly coupling with the induction coil. The innermost layer is an alumina tube that diffuses the heat generated by the susceptor enabling a controlled, uniform hot zone around the sensor. An additional S-type thermocouple, connected to the PID temperature controller for the induction furnace, is inserted from the bottom of the MFHR-TA apparatus within $6 \mathrm{~mm}$ from the bottom of the sensor (not shown in Fig. 1a). As is typical for analog calorimetric measurements, reliable temperature control is not possible from the sensor thermocouple when the sample experiences significant endothermic or exothermic events. The thermocouple connected to the PID temperature controller is used for heating rates up to $150{ }^{\circ} \mathrm{C} \mathrm{min}^{-1}$ and the maximum heating rate is dependent on the mass and thermal conductivity of the sample. Higher heating rates require that the induction furnace operates at constant power with no feedback control because the limits of thermal transfer from the susceptor to the controlling thermocouple do not allow enough time for the feedback loop to control without temperature overshoot.

The induction coil, labeled and displayed schematically in Fig. 1b, is built inside an aluminum insert that is lowered into the bore of the superconducting magnet. The MFHR-TA apparatus is fed into the induction coil insert to complete the test setup. Induction heating provides a compact heating source with high energy density and low thermal mass allowing for extremely rapid heating and the ability to gas quench for mimicking process conditions.

Ideally, the wall of the graphite susceptor should be thick enough to effectively shield the sample and sensor from RF energy used to heat the furnace. The penetration is determined by the skin depth given by $\delta=\sqrt{\left(\frac{2 \rho}{\omega \mu}\right)}$, where $\rho$ is the electrical resistivity, $\omega$ is the angular frequency, and $\mu$ is the permeability. Due to a wide range of reported resistivity values for fine grained polycrystalline graphite, an experimentally determined resistivity value of $9.64 * 10^{-6} \Omega \mathrm{m}$ was measured from the graphite material used in the apparatus. At a frequency of $165 \mathrm{kHz}$, the calculated skin depth [30] is $3.8 \mathrm{~mm}$ which exceeds the thickness of the graphite $(3.2 \mathrm{~mm})$, and thus the susceptor would be expected to attenuate the RF energy by about $60 \%$. For this reason, there was a need to determine the effect the coil may have on a sample that is susceptible to the electromagnetic signal. The thickness of the susceptor balances the ability to shield the sample from and couple adequately to the induction field with a

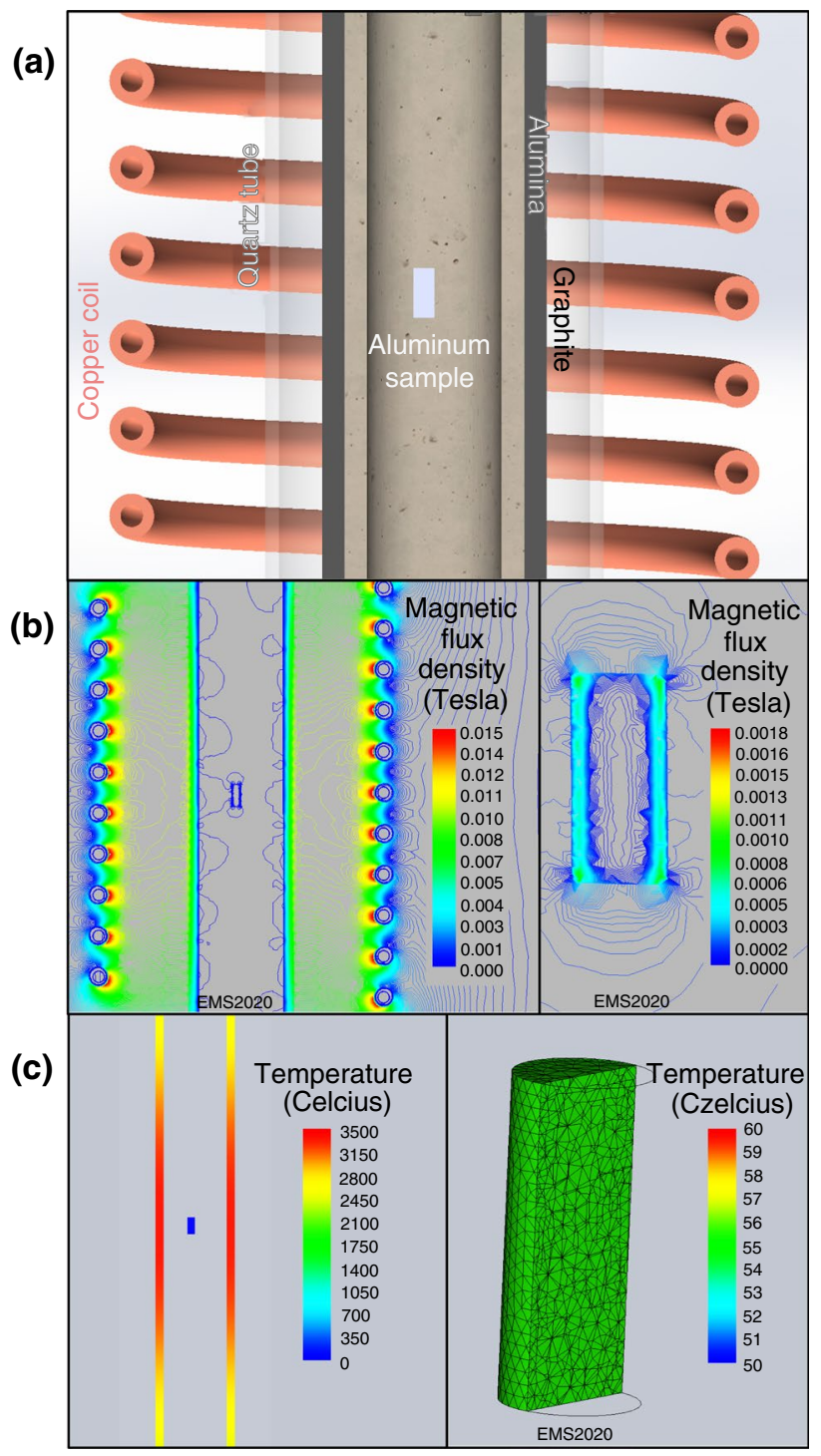

Fig. 2 Electromagnetic simulation showing a the to-scale rendering of the induction coil and MFHR-TA apparatus with the steady state $\mathbf{b}$ magnetic flux density and $\mathbf{c}$ temperature in the graphite susceptor and an aluminum sample at $80.4 \mathrm{Amps}$ and $165 \mathrm{kHz}$

desire to reduce thermal mass for temperature responsiveness.

Using SOLIDWORKS Professional 2019 SP5 with the add-in module EMS 2020 SP2 by EMWorks, a to-scale parametric model (Fig. 2a) of the MFHR-TA apparatus and induction coil was built to simulate (1) the magnetic flux density absorbed by the graphite susceptor and an aluminum sample (Fig. 2b) and (2) the respective temperatures (Fig. 2c) reached at steady state assuming no thermal transport from component to component. This assumption was made in order to isolate the effect of the induction coil on the susceptible components, i.e., the graphite and the metallic sample. Another assumption that should be noted is the 
steady-state condition does assume equal heat flow into and out of a component, but the heat out does not transfer to other components in the model. Material properties were taken from the internal materials library included with the EMS module, except for the graphite resistivity, which was experimentally determined using a 4-point resistivity measurement. Mesh size control constraints are applied to the two components of interest. The mesh control limit on the outer edge of the graphite is $1 \mathrm{~mm}$, while the aluminum sample mesh was controlled by applying a node every 6 degrees about the circumference of the top and bottom edges of the cylinder (mesh shown in Fig. 2c (right)). There were over 15,000,000 total number of elements in the model. The simulation was run at $80.4 \mathrm{~A}$ and a frequency of $165 \mathrm{kHz}$. In Fig. 2b, the magnetic flux density diminishes as it penetrates through the graphite, though some signal reaches the edge of the sample at approximately $0.001 \mathrm{~T}$. At steady state, this signal results in a sample temperature of approximately $55^{\circ} \mathrm{C}$ (Fig. 2c (right)), while the susceptor reaches a maximum temperature of $3362{ }^{\circ} \mathrm{C}$ (Fig. 2c (left)). The practical effect of this signal reaching the sample/sensor area was not observable in the data presented in this manuscript, though quantitative calculations of heat capacity or enthalpy of transformation may be affected, so elimination of this signal is preferable. Potential routes to mitigate this shielding issue in future iterations of this instrument include: (1) acquire a power supply for a higher frequency and a shallower skin depth, (2) increase the thickness of the graphite susceptor, and (3) change the susceptor material to a material with higher resistivity or permeability (cobalt, for instance).

\section{Signal processing}

Because the voltage output from the sensor is relatively low (e.g., millivolts), measurements are especially subject to contamination from nearby electromagnetic sources that could introduce noise. Contamination of the DC voltage output of a thermocouple can be caused by other DC voltages and by $\mathrm{AC}$ voltages induced from external sources such as an induction power supply. Induction systems pose a particular challenge for thermal analysis due to potential AC voltage contamination. It is desirable to obtain the largest signalto-noise ratio possible; however, the small magnitude output of a thermocouple can require significant amplification and high noise rejection to achieve a desirable signal-to-noise ratio. The precious metal thermocouple types (e.g., S, R, and B) are especially vulnerable to signal noise contamination. These low amplitude signals require higher gain, precision, and stability in the signal amplification electronics. Induction heating power supplies operate with resonant tank circuits controlled by pulse-width modulation. Systems of the size considered here are typically driven by power delivering tens of kilowatts, with operating frequencies range from 1 to $1 \mathrm{MHz}$, and noise and harmonics generated across the spectrum to tens of $\mathrm{MHz}$. The noise and disruptive signals can render many data acquisition and control systems useless unless processing through filtering and protection through good grounding practice is followed.

Analog electronic circuits at the signal input points are particularly susceptible to stray radio frequency interference (RFI) in addition to the electromagnetic interference (EMI) from the RF coil used here. This susceptibility occurs when the coupled RFI/EMI signal is rectified (envelope demodulated) by nonlinear junctions at the first stage of semiconductors employed in a data acquisition system. Because of the demodulation effect, these circuits present a noise-derived signal that is in the same frequency band (at or near DC) as the thermocouple signals of interest. Such contamination cannot be removed by subsequent software filtering, so hardware filtering is required. Hardware filter types that can be implemented are Butterworth, Elliptical, Bessel, and multistage filters. Multistage hardware filters have been developed as part of this work [31].

Figure 3 displays the signal over three stages of filtering. Figure $3 \mathrm{a}$ (top) shows the $165 \mathrm{kHz} \mathrm{AC}$ currents applied to the induction coil. The data were recorded from a constant power output of $2506 \mathrm{~W}$. The applied AC current generally has two characteristic frequencies that result in
Fig. 3 Signal input and output for the induction system at $2506 \mathrm{~W}$ and DSC sensor. a The $\mathrm{AC}$ excitation current to the induction coil (top), the raw signal DC voltage output from the sensor thermocouple (middle), and the final processed signal after filtering (bottom). Note the change in voltage scale. b Digitized thermocouple signal with and without software filtering at top and bottom, respectively
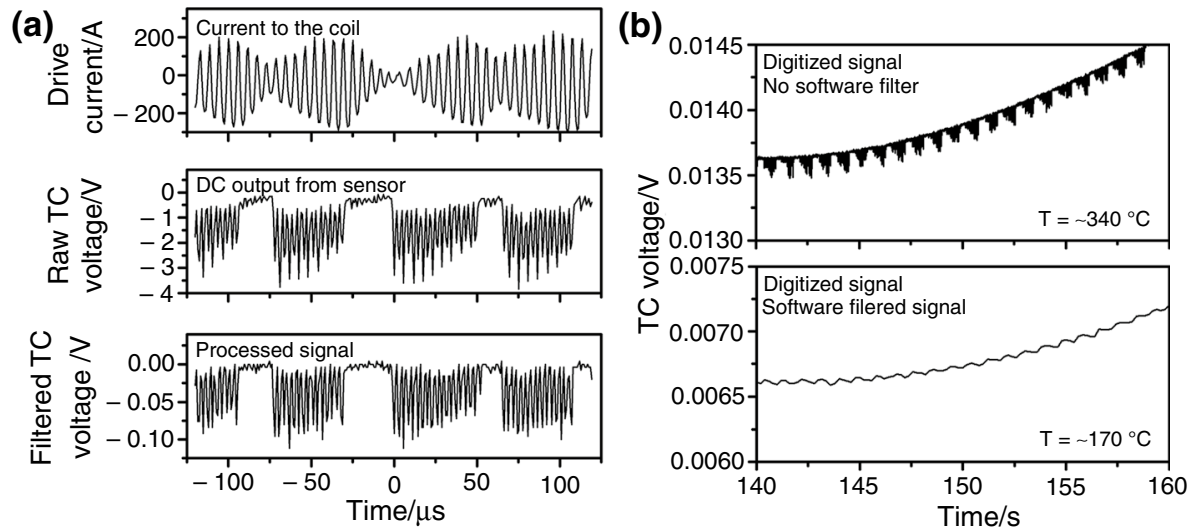
an inner-modulated AC excitation current. The higher frequency modulation, typically greater than $100 \mathrm{kHz}$, is a result of the natural resonant frequency of the RF resonant circuit. This component is typically inner-modulated with a frequency that is characteristic to the duty cycle control of the output power from a drive circuit that delivers power to the susceptor. The resulting AC current causes the induction coil to heat the furnace susceptor, which in turn heats the sample and the reference.

As the sample and reference are heated, thermocouples measure the resulting temperature changes. As explained above, the thermocouples output a DC voltage, which is superimposed on an AC voltage output caused by induced EMF from interactions with the RF field. Figure 3a (middle) shows example voltage outputs from a thermocouple measuring the temperature of a sample when the AC excitation of Fig. 3a (top) is applied to the induction coil. As shown in Fig. 3a (middle), the voltage output may have a DC component and an AC component. Figure 3a (bottom) shows example signals after the voltage output of the thermocouple measuring sample temperature is passed through an analog filter. The signal is then digitized and Fig. $3 \mathrm{~b}$ (top) shows an example signal (recorded during an experiment with the sensor temperature near $340^{\circ} \mathrm{C}$ ). Lastly, the signal is passed through a digital, high order Butterworth low-pass software filter (e.g., greater than fourth order), which can remove virtually all remaining high-frequency noise. An example of a final software-filtered signal (recorded during a separate experiment with the sensor temperature near $170{ }^{\circ} \mathrm{C}$ ) is displayed in Fig. 3b (bottom).

\section{Thermal performance and testing}

The performance of the thermal analyzer was verified by melting and solidifying two high purity samples of aluminum and gold with temperature scan rates of 5, 10, 20, 50 and $100^{\circ} \mathrm{C} \mathrm{min}^{-1}$ in an argon atmosphere. Figure 4 shows plots of the differential thermocouple voltage signal vs. sample temperature for each of these temperature scan rates. These results show that there is a substantially noise-free baseline that is maintained under high RF electromagnetic energy. The onset of melting upon heating and solidification upon cooling is shown in Table 1. The melting point of the samples is observed at temperatures that measurably increase only at the rate of $100{ }^{\circ} \mathrm{C} \mathrm{min}{ }^{-1}$ due to thermal lag between the sample and the reference. The transformation temperature due to undercooling is virtually unchanged as a result of cooling rate (see Table 1). From the standard melting temperatures of 660 and $1064^{\circ} \mathrm{C}$ for $\mathrm{Al}$ and $\mathrm{Au}$, respectively, a calibration offset for the instrument of $-8{ }^{\circ} \mathrm{C}$ is determined.
Fig. 4 Melting calibration at various heating rates for $\mathbf{a} \mathrm{Al}$ and $\mathbf{b} \mathrm{Au}$
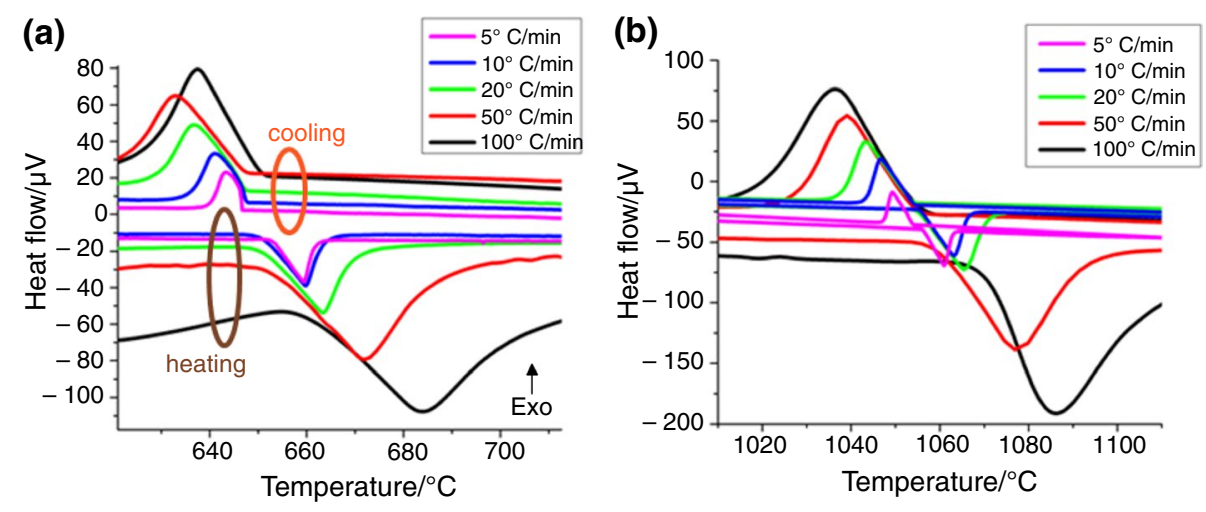

Table 1 Measured, uncalibrated melting and solidification temperatures of pure $\mathrm{Al}$ and $\mathrm{Au}$ determined from calibration runs at various heating and cooling rates

\begin{tabular}{|c|c|c|c|c|}
\hline & $\mathrm{Al}_{\text {Melting }} /{ }^{\circ} \mathrm{C}$ & $\mathrm{Al}_{\text {Solidification }} /{ }^{\circ} \mathrm{C}$ & $\mathrm{Au}_{\text {Melting }} /{ }^{\circ} \mathrm{C}$ & $\mathrm{Au}_{\text {Solidification }}{ }^{\circ} \mathrm{C}$ \\
\hline $5^{\circ} \mathrm{C} \min ^{-1}$ (Ar) & 653 & 647 & 1056 & 1053 \\
\hline $10^{\circ} \mathrm{C} \min ^{-1}(\mathrm{Ar})$ & 651 & 648 & 1056 & 1054 \\
\hline $20^{\circ} \mathrm{C} \min ^{-1}(\mathrm{Ar})$ & 651 & 648 & 1055 & 1054 \\
\hline $50{ }^{\circ} \mathrm{C} \min ^{-1}(\mathrm{Ar})$ & 652 & $648^{*}$ & 1058 & $1054 *$ \\
\hline $100{ }^{\circ} \mathrm{C} \min ^{-1}(\mathrm{Ar})$ & 661 & $651^{*}$ & 1070 & $1054^{*}$ \\
\hline $500{ }^{\circ} \mathrm{C} \min ^{-1}(\mathrm{Ar})$ & 729 & $652^{*}$ & - & - \\
\hline $500{ }^{\circ} \mathrm{C} \min ^{-1}(\mathrm{He})$ & 663 & $646^{*}$ & - & - \\
\hline
\end{tabular}

*All cooling rates are controlled and constant at and below $20{ }^{\circ} \mathrm{C} \mathrm{min}^{-1}$. PID controlled furnace cooling rates are limited to rates up to $30{ }^{\circ} \mathrm{C} \mathrm{min}^{-1}$ for $\mathrm{Ar}$ and $83{ }^{\circ} \mathrm{C} \mathrm{min}-1$ for $\mathrm{He}$ atmospheres due to the thermal mass of the system 


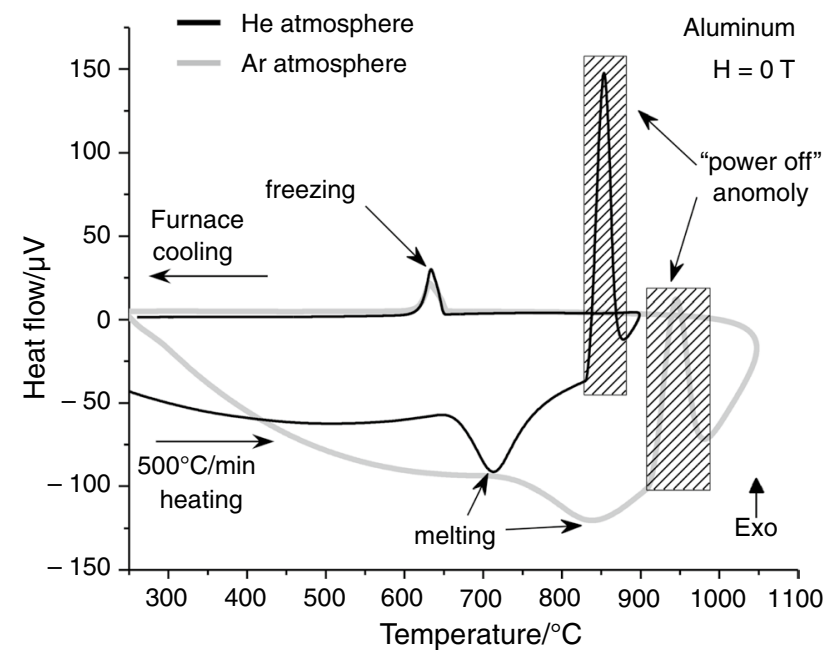

Fig. 5 Effect of carrier gas on signal response at high heating rates during the melting of aluminum. The "power off" anomalies are transient effects that occur when power to the induction coil is turned off and likely due to the coil signal reaching the sample/sensor shown in Fig. 2

While conventional high-temperature calorimeters can reach heating rates up to $100{ }^{\circ} \mathrm{C} \mathrm{min}^{-1}$, with the use of induction heating, significantly higher heating rates are achievable. The challenge then becomes effective heat transfer from the environment to the specimen and from specimen and reference to the sensor. To improve this thermal coupling, a carrier gas with high thermal conductivity like helium can be used. Figure 5 compares results from melting aluminum in argon and in helium at an extreme rate by using a constant applied current of $140 \mathrm{~A}$. This results in an average heating rate of $\sim 500{ }^{\circ} \mathrm{C} \mathrm{min}{ }^{-1}$ from 500 to $800{ }^{\circ} \mathrm{C}$. The increased thermal coupling with helium results in a clear improvement in melting peak sharpness and reduction in thermal lag (overheating). As the system furnace cools in both runs, the solidification peaks start at the same temperature, but helium again results in a sharper peak shape. Helium is known to be a more effective carrier gas for rapid response, but it is also more sensitive to flow rate and other fluctuations, so noise can be a limiting factor for measurements of lesser signal intensity (i.e., lower energy transformations).

The thermal analyzer was also tested under high magnetic field environments generated by large bore superconducting magnets in the configuration shown in Fig. 1. Samples of high purity aluminum were melted under 0 or 9 Tesla DC magnetic fields at $10{ }^{\circ} \mathrm{C} \mathrm{min}{ }^{-1}$. The melting point of aluminum is not expected to be significantly affected by the large magnetic fields $[15,32]$. These results, using the calibration offset determined above, are shown in Fig. 6. There is virtually no difference in the measured results in the high magnetic field environment

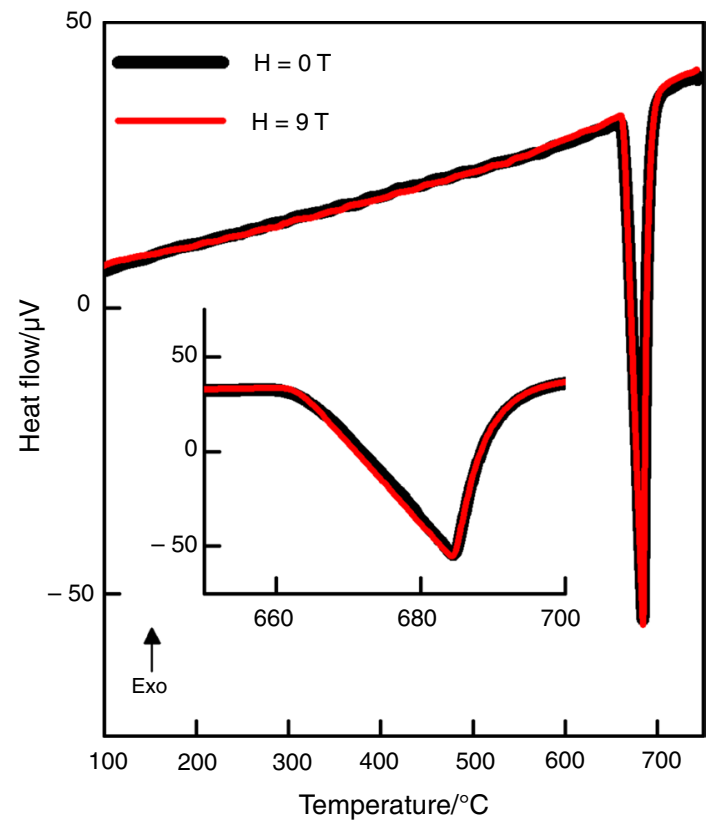

Fig. 6 Aluminum melting at $10{ }^{\circ} \mathrm{C} \mathrm{min}^{-1}$ in applied fields of zero and $9 \mathrm{~T}$

compared to an environment with no magnetic field, the measured melting temperature is 660 and $661{ }^{\circ} \mathrm{C}$, respectively. This shows that the thermal analyzer can successfully operate in a high magnetic field environment, and the sensitivity and thermal response of the instrument is not affected by the field under these conditions.

\section{Thermal analysis at industrially relevant processing rates and in high magnetic fields}

The heat treatments that many materials undergo require direct insertion into a furnace already set at the target temperature in order to get the material to temperature as rapidly as possible. For rapidly transforming materials, it can be difficult to know at what temperature transformations begin. Currently, there is no DSC system capable of inserting a sensor with a sample directly into a hot zone to observe thermal events; however, the rapid heating that electromagnetic induction provides is a close analog to these process-relevant heating rates. In Fig. 7, pure copper is melted at an extreme heating rate of $950{ }^{\circ} \mathrm{C} \mathrm{min}^{-1}$ through the temperature range between 950 and $1100^{\circ} \mathrm{C}$. The constant power mode simulates the direct insertion of a sample into a furnace at temperature and the ability of the thermal analyzer to measure an accurate transformation temperature in real time. The standard melting temperature of copper is $1085^{\circ} \mathrm{C}$, and from these data, a melting temperature of $1086^{\circ} \mathrm{C}$ is determined. 


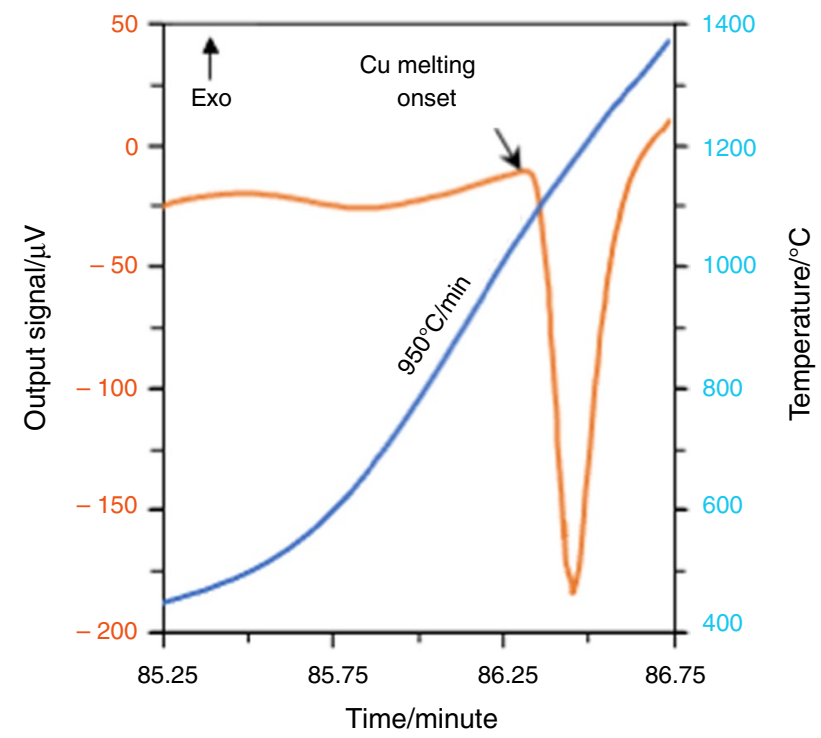

Fig. 7 High heating rate of $950{ }^{\circ} \mathrm{C} \min ^{-1}$ through the melting temperature of pure copper

Engineering materials often require heat treatments involving rapid cooling to avoid adverse phase formation or to kinetically trap parent phases (i.e., solutionizing and quenching) on the processing route to obtain optimal properties. These heat treatments are designed using calculated phase diagrams and time-temperature transformation (TTT) or continuous cooling transformation (CCT) diagrams. Ex situ characterization techniques like metallography, optical and scanning electron microscopy, and X-ray diffraction are needed to gather the data to build the abovementioned diagrams and to analyze the phases present and microstructural morphology of heat-treated material. It is a time consuming and costly endeavor to build a TTT or CCT diagram for a new material. The MFHR-TA has the ability to identify transformation temperatures at rapid cooling rates. By varying the cooling rate and precisely logging the transformation temperatures, this instrument can collect data for these diagrams at a much more rapid rate than the ex situ methods. Figure 8a shows the MFHR-TA cooling curves from a proprietary ferrous alloy undergoing an austenite to ferrite phase transformation (black and orange arrows indicate onset) at slow $\left(23^{\circ} \mathrm{C} \mathrm{min}{ }^{-1}\right)$ and intermediate $\left(47^{\circ} \mathrm{C} \mathrm{min}^{-1}\right)$ cooling rates, along with the fast $\left(77^{\circ} \mathrm{C} \mathrm{min}^{-1}\right)$ cooling rate (blue curve) showing no transformation. The cooling rates were measured as an average over the transformation temperature range. Sweeping through a transformation faster, (i.e., $47^{\circ} \mathrm{C} \mathrm{min}{ }^{-1}$ versus $23^{\circ} \mathrm{C} \mathrm{min}^{-1}$ ) results in a significant increase in signal, as expected, due to the heat flow value's dependence on both time and temperature. This is observed in the peak intensity of the transformations for the slow and intermediate cooling rates. The continuous cooling curves in Fig. $8 \mathrm{~b}$ show the transformations at specific time and temperature points and the development of a 'nose' indicating the start of the ferrite region the CCT diagram.

Austenite and martensite starting temperatures in steels and their dependence on magnetic fields can be identified using this instrument. Figure $9 \mathrm{a}$ shows a heating and $\mathrm{He}$ quenching profile for a steel sample. Figure $9 \mathrm{~b}$ is a output signal vs temperature plot showing a peak associated with austenite formation upon heating and martensite formation at lower temperature $\left(224^{\circ} \mathrm{C}\right)$ during the He quench. Because of the rapid nature of the cooling process and the sensitivity of this sort of measurement, repeatability is a concern. Figure $9 \mathrm{c}$ and $d$ shows overlays of two thermal analysis experiments (red curves) confirming excellent reproducibility of the austenite and martensite transformations. The curves are translated vertically on the y-axis for ease of visualization but are otherwise unchanged from the raw data output. The same tests were conducting under a $9 \mathrm{~T}$ magnetic field (blue curves in Fig. 9c and d) and these results also showed good reproducibility. Table 2 lists the start temperatures (marked with black arrows in Fig. 9c and d) for austenite and martensite, and for a given test condition, the measured values are all within $7{ }^{\circ} \mathrm{C}$ or less. An important observation when comparing the $0 \mathrm{~T}$ to the $9 \mathrm{~T}$ results is the increase in the austenite and martensite start temperatures under field, particularly, the $\sim 60{ }^{\circ} \mathrm{C}$ change for austenite, as it is consistent with previous predictions in calculated phase diagrams [17].
Fig. 8 a MFHR-TA and b continuous cooling curves showing the ferrite transformation temperature at various cooling rates
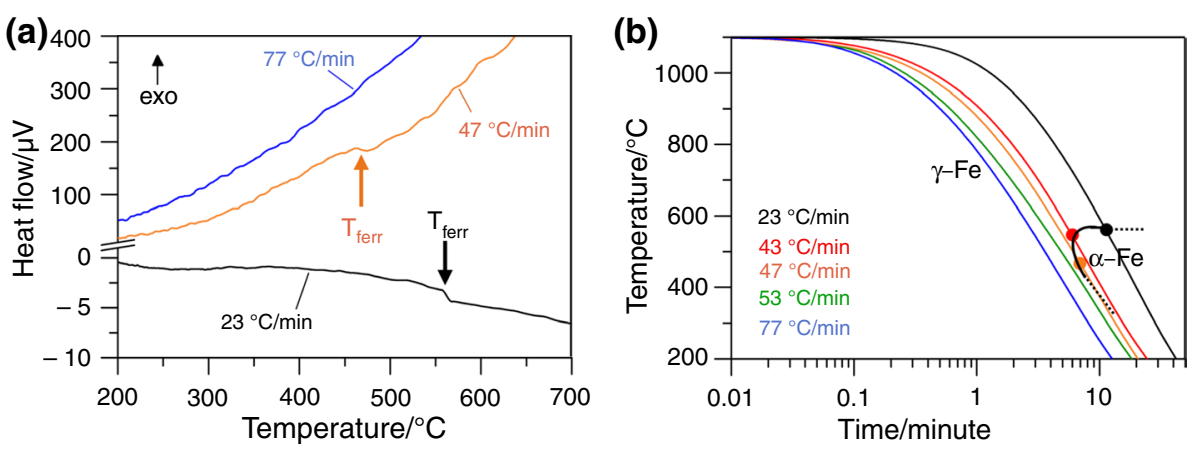
Fig. 9 a The heating and $\mathrm{He}$ quench profile for an austenitic steel and the resulting $\mathbf{b}$ MFHRTA data showing austenite transformation upon heating and martensite formation upon quenching. MFHR-TA results showing peaks representing c austenite transformations upon heating and $\mathbf{d}$ martensite transformations upon cooling at 0 and $9 \mathrm{~T}$. Two tests at each magnetic field are shown to demonstrate repeatability during both heating and gas quenching

Table 2 Austenite and martensite start temperatures as measured by the tangent method

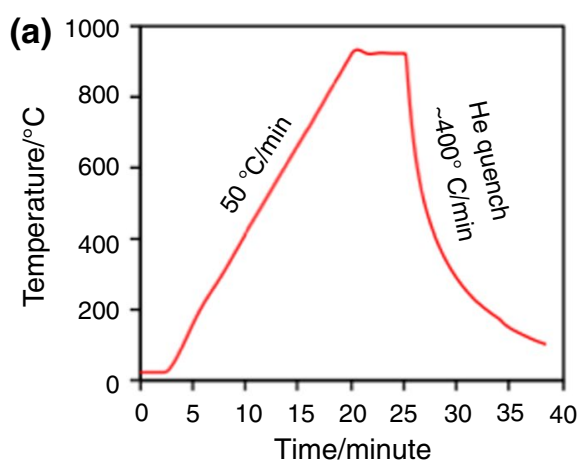

(c)

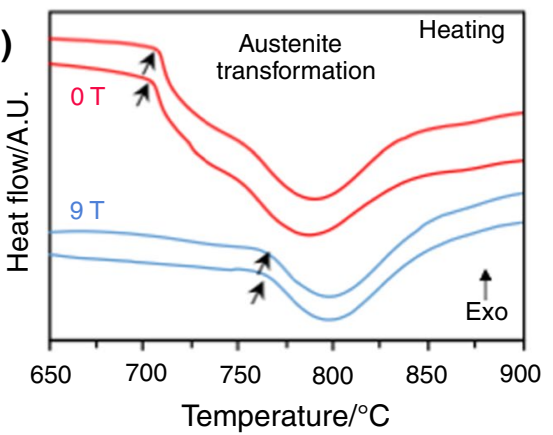

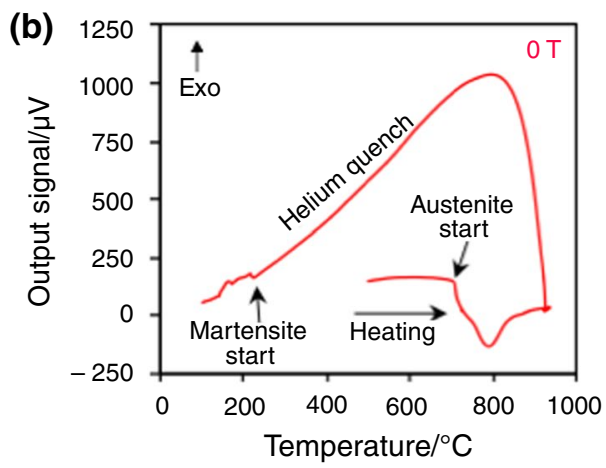

(d)

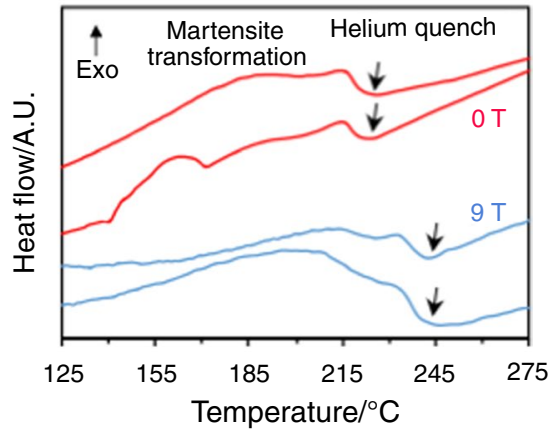

\begin{tabular}{lcc}
\hline & $0 \mathrm{~T}$ & $9 \mathrm{~T}$ \\
\hline Austenite Start $/{ }^{\circ} \mathrm{C}$ & 704 & 764 \\
& 706 & 765 \\
& 708 & 763 \\
Martensite Start $/{ }^{\circ} \mathrm{C}$ & 230 & 244 \\
& 224 & 243 \\
& 223 & 246 \\
\hline
\end{tabular}

in place of the argon atmosphere. An example of using various cooling rate data from the instrument to examine phases, diagrams, and measurements in applied magnetic fields up to $9 \mathrm{~T}$ is demonstrated and used to show the effect of field on phase transformations in steel. Development of this instrument and technique should allow new regimes of materials processing to be explored by thermal analysis and provide a deeper understanding of the thermodynamic and kinetic effects of magnetic fields applied during thermomagnetic processing.

\section{Summary and conclusions}

A new thermal analysis technique, Magnetic Field/High Rate Thermal Analysis, is introduced. A description of the custom, induction-powdered, high magnetic field compatible thermal analysis apparatus is presented, and the signal processing is discussed. The example measurements shown here demonstrate the ability of the instrument to gather accurate data at rapid heating and cooling rates, versatile environments, and at applied magnetic fields. Appropriate hardware and software filtering of the thermocouple signals allows accurate measurements of temperature despite the extremely noisy environment inside the magnet and induction furnace. Typical heating cooling rates can be achieved using PID control, and extreme heating rates approaching and likely exceeding $1000^{\circ} \mathrm{C} \mathrm{min}^{-1}$ can be realized by applying a constant high power to the furnace. Temperature accuracy at high rates is greatly improved by using the more thermally conductive helium

Acknowledgements This work is supported by the Critical Materials Institute, an Energy Innovation Hub funded by and performed under the auspices of the U.S. Department of Energy, Office of Energy Efficiency and Renewable Energy, Advanced Manufacturing Office at Oak Ridge National Laboratory under contract DE-AC05-00OR22725 and at by Lawrence Livermore National Laboratory under contract DE-AC52-07NA27344.

Author contributions All authors contributed to data collection and rendering. The manuscript was written by Michael S. Kesler and cowritten by Michael A. McGuire and Orlando Rios. SOLIDWORKS model and simulation were designed and run by Bart Murphy. Instrument fabrication was performed by Ben Conner, Orlando Rios, and William Carter.

Data availability Patent is available online, and data is available upon request.

\section{Declarations}

Conflict of interest The authors declared that they have no competing interest. 
Open Access This article is licensed under a Creative Commons Attribution 4.0 International License, which permits use, sharing, adaptation, distribution and reproduction in any medium or format, as long as you give appropriate credit to the original author(s) and the source, provide a link to the Creative Commons licence, and indicate if changes were made. The images or other third party material in this article are included in the article's Creative Commons licence, unless indicated otherwise in a credit line to the material. If material is not included in the article's Creative Commons licence and your intended use is not permitted by statutory regulation or exceeds the permitted use, you will need to obtain permission directly from the copyright holder. To view a copy of this licence, visit http://creativecommons.org/licenses/by/4.0/.

\section{References}

1. Watson ES, O'Neill MJ, Justin J, Brenner N. Anal Chem. 1964;36:1233.

2. O'Neill MJ. Anal Chem. 1964;36:1238.

3. McGregor C, Bines E. Int J Pharm. 2008;350:48.

4. Saunders M, Podluii K, Shergill S, Buckton G, Royall P. Int J Pharm. 2004;274:35.

5. Efremov MYu, Olson EA, Zhang M, Lai SL, Schiettekatte F, Zhang ZS, Allen LH. Thermochim Acta. 2004;412:13.

6. Minakov AA, Schick C. Thermochim Acta. 2015;603:205.

7. Poel GV, Mathot VBF. Thermochim Acta. 2007;461:107.

8. Vyazovkin S, Koga N, Schick C. Handbook of Thermal Analysis and Calorimetry: Recent Advances. Techniques and Applications: Elsevier; 2018.

9. Danley RL, Caulfield PA, Aubuchon SR. Am. Lab. 2008;40:9.

10. Lai S, Guo J, Petrova V, Ramanath G, Allen L. Phys Rev Lett. 1996;77:99.

11. Pijpers TFJ, Mathot VBF, Goderis B, Scherrenberg RL, van der Vegte EW. Macromolecules. 2002;35:3601.

12. Badrinarayanan P, Kessler MR. J Chem Educ. 2010;87:1396.

13. Liu P, Yu L, Liu H, Chen L, Li L. Carbohydr Polym. 2009;77:250.

14. Li C, Ren Z, Ren W. Mater Lett. 2009;63:269.

15. Minohara M, Tozaki K, Hayashi H, Inaba H. J Therm Anal Calorim. 2006;86:833.

16. Jaramillo R, Ludtka G, Kisner R, Nicholson D, Wilgen J, Mackiewicz-Ludtka G, Bembridge N, Kalu P, "Investigation of phase transformation kinetics and microstructural evolution in 1045 and 52100 steel under large magnetic fields", Solid-Solid Phase Trans Inorgan Mater. 2005.

17. Jaramillo RA, Babu SS, Ludtka GM, Kisner RA, Wilgen JB, Mackiewicz-Ludtka G, Nicholson DM, Kelly SM, Murugananth M, Bhadeshia HKDH. Scr Mater. 2005;52:461.

18. Choi J-K, Ohtsuka H, Xu Y, Choo W-Y. Scr Mater. 2000;43:221.

19. Enomoto M. Mater Trans. 2005;46:1088.

20. Ludtka GM, Jaramillo RA, Kisner RA, Nicholson DM, Wilgen JB, Mackiewicz-Ludtka G, Kalu PN. Scr Mater. 2004;51:171.

21. Kesler MS, Jensen B, Zhou L, Palasyuk O, Kim T-H, Kramer MJ, Nlebedim IC, Rios O, McGuire MA. Magnetochemistry. 2019;5:16.

22. McGuire MA, Rios O, Conner BS, Carter WG, Huang M, Sun K, Palasyuk O, Jensen B, Zhou L, Dennis K, Nlebedim IC, Kramer MJ. J Magn Magn Mater. 2017;430:85.

23. Ohtsuka H. Sci Technol Adv Mater. 2008;9:013004.

24. Joo HD, Kim SU, Koo YM, Shin NS, Choi JK. Metall Mater Trans A. $2004 ; 35: 1663$.

25. Rivoirard S. JOM. 2013;65:901.

26. Sun ZHI, Guo M, Vleugels J, Van der Biest O, Blanpain B. Curr Opin Solid State Mater Sci. 2012;16:254.

27. Ahmad A, Mackiewicz-Ludtka G, Pfaffmann G, Ludtka GM. Adv Mater Process. 2016;174.

28. Ludtka G, Mackiewicz-Ludtka G, Pfaffmann G. Ind Heat. 2013;8:43.

29. Byvank T, Conner BS, Kisner RA, McGuire MA, Rios O, Kesler MS, Ludtka GM, Evans B, Niebedim CI, McCallum RW. U.S. Patent 10,782,193; issued 22 September 2020.

30. Jordan E, Balmain K. Electromagn Waves and Radiat Syst. Prentice Hall; 1968.

31. Kisner RA, Fugate DL. U.S. Patent 9,490,766 B2; issued 8 November 2016.

32. Kimura T. Jpn J Appl Phys. 2001;40:6818.

Publisher's Note Springer Nature remains neutral with regard to jurisdictional claims in published maps and institutional affiliations. 